\title{
Obesity, a serious etiologic factor for male subfertility in modern society
}

\author{
Yue Liu and Zhide Ding \\ Department of Histology, Embryology, Genetics and Developmental Biology, Shanghai Key Laboratory for \\ Reproductive Medicine, School of Medicine, Shanghai Jiao Tong University, Shanghai, China \\ Correspondence should be addressed to Z Ding; Email: zding@shsmu.edu.cn
}

\begin{abstract}
Obesity, defined as excessive accumulation of fat in adipose tissue, is a metabolic disorder resulting from behavioral, environmental and heritable causes. Obesity increases the risks of hypertension, diabetes, cardiovascular disease, sleep apnea, respiratory problems, osteoarthritis and cancer. Meanwhile, the negative impact of obesity on male reproduction is gradually recognized. According to the clinical investigations and animal experiments, obesity is correlated with reductions in sperm concentration and motility, increase in sperm DNA damage and changes in reproductive hormones. Several mechanisms can elucidate the effects of obesity on sperm functions and male subfertility, i.e., the excessive conversion of androgens into estrogens in redundant adipose tissue causes sexual hormone imbalance, subsequently resulting in hypogonadism. Secondly, adipokines produced by adipose tissue induce severe inflammation and oxidative stress in male reproductive tract, directly impairing testicular and epididymal tissues. Moreover, increased scrotal adiposity leads to increase gonadal heat, continuously hurting spermatogenesis. Therefore, obesity alters the systematic and regional environment crucial for spermatogenesis in testis and sperm maturation in epididymis, and finally results in poor sperm quality including decreased sperm motility, abnormal sperm morphology and acrosome reaction, changed membrane lipids and increased DNA damage. Furthermore, recent studies indicate that epigenetic changes may be a consequence of increased adiposity. A major effort to identify epigenetic determinants of obesity revealed that sperm DNA methylation and non-coding RNA modification are associated with BMI changes and proposed to inherit metabolic comorbidities across generations. This review will explain how obesity-related changes in males to influence sperm function and male fertility as well.

Reproduction (2017) 154 R123-R131
\end{abstract}

\section{Introduction}

Obesity is a metabolic disease determined by lifestyle such as physical activity, environmental factors (food variety and intake) and genetic factors. In recent decades, it becomes a major health problem and increases worldwide at an alarming rate. Approximately 1.9 billion people are overweight (body mass index $(\mathrm{BMI}) \geq 25 \mathrm{~kg} / \mathrm{m}^{2}$ ) or affected by obesity (BMI $\geq 30 \mathrm{~kg}$ / $\mathrm{m}^{2}$ ) in the world (World Health Organization 2014) and are at risk of developing type 2 diabetes, cardiovascular disease and related metabolic and inflammatory disturbances. Additionally, there is growing interest and progress in understanding the impact of obesity on male reproduction. Recently, both clinical and experimental reveal the negative consequences of obesity on male reproductive function. According to the clinical investigation, men with overweight or obesity can decrease sperm quality including sperm concentration, sperm motility, acrosome reaction decline, increased sperm DNA damage and lower embryo implantation rates as well, comparing to those of normal BMI men (Jensen et al. 2004, Dupont et al. 2013,
Sermondade et al. 2013, Samavat et al. 2014, Shukla et al. 2014, McPherson et al. 2015, Soubry et al. 2016). In consequence, obesity was associated with a more than $20 \%$ increased cases of subfertility and infertility (Cui et al. 2016).

Notably, male fertility depends on certain amounts of spermatozoa with sufficiently high quality. The spermatogenesis and sperm maturation are highly complex and specialized processes under strictly regulatory mechanisms, which are involved in the sex steroids, testicular niche, Sertoli cells, epididymic fluid and so on. However, there is an undisputed fact that obesity affects male reproductive potential. In general, the excessive visceral adiposity in obese individual leads to the changes in hormone levels and promotes chronic inflammation in reproductive tract (MacDonald et al. 2010, Dulloo \& Montani 2012), and high fat content in scrotum area also causes an increase in scrotal temperature. Thus, all these consequences of obesity subsequently can damage the microenvironments of testes and epididymis, which are crucial for the production and maturation of spermatozoa. In practical terms, 
obesity primarily impairs the physical and molecular structure of sperm during both spermatogenesis in testis and sperm maturation in epididymis, finally reducing sperm quality and causing male infertility risk.

\section{Obesity leads to hypogonadism}

Male obesity is associated with hypogonadism. Most obese males have altered reproductive hormonal profiles, e.g. elevated estrogen and leptin levels, and decreased testosterone, follicle-stimulating hormone $(\mathrm{FSH})$, sex hormone-binding globulin (SHBG), ghrelin and inhibin B levels (MacDonald et al. 2010, McPherson \& Lane 2015, Martins et al. 2015, 2016, Cui et al. 2017). In obese men, the hyperactivity of aromatase (cytochrome P450 enzyme) in redundant white adipose tissue causes excessive conversion of androgens into estrogens. Therefore, gonadotrophin secretion from the pituitary decreases through feedback inhibition on the hypothalamus and pituitary gland, and then further impacts on testosterone production through falls in gonadotrophin-releasing hormone (GnRH)-luteinizing hormone (LH)/FSH pulses (Mah \& Wittert 2010, Michalakis et al. 2013, Rey et al. 2013). The disruption of the negative feedback loop of the hypothalamic pituitary gonadal (HPG) axis finally leads to the significant decline in testosterone production.

Undoubtedly, these sexual hormone imbalances may be one of the important causes for male infertility or subfertility induced by obesity. It is known that, both testicular development at puberty and spermatogenesis maintenance at adult depend on a high level of testosterone. Normal intra-testicular testosterone levels are 50-100 times comparing to that in serum. Actually, this high level intra-testicular testosterone is required for maintenance of the blood-testis barrier (BTB), the specific cell junctions between Sertoli cells, as well as maintenance of the cell adhesion between Sertoli cells and germ cells (Lie et al. 2013). Meanwhile, testosterone is indispensable in meiotic progression and spermatid maturation. Thus, the high levels of testosterone, associated with Sertoli cells, construct the niche suitable for the developing germ cells throughout the different phases of spermatogenesis. Additionally, FSH is another important regulator of Sertoli cells, stimulating virtually all functions related to spermatogenesis. Therefore, the low testosterone and FSH levels in obese men can be a cause for impaired spermatogenesis and finally lead to reduced sperm counts and subfertility (Cheng et al. 2010, Ramaswamy \& Weinbauer 2015).

\section{Obesity induces inflammation}

Accumulated evidences suggested a positive correlation between chronic inflammation or proinflammation state and human obesity, while parallel relationships have been observed in animal models
(Divella et al. 2016, Griffin et al. 2016, Kolb et al. 2016). The white adipocytes produce and secrete a large number of molecules, collectively called adipocytokines or adipokines, and the majority of adipokines, such as tumor necrosis factor- $\alpha$ (TNF- $\alpha$ ), interleukins (IL-1, IL-6 and IL-18) are pro-inflammatory cytokines, which are the mediators of inflammation and will further increase inflammation and attract macrophages. It is thought that pro-inflammatory cytokines contribute to the disruption in glucose homeostasis and insulin resistance that are often linked with obesity. Besides the adipocytes, these pro-inflammatory cytokines, such as TNF- $\alpha$ and IL-6, are also increased in the serum, testicular tissue and the seminal plasma of obese males (Zhang et al. 2015, Huang et al. 2016).

It is now well documented that pro-inflammatory cytokines exert some impacts on the HPG axis and on fertility (Tsatsanis et al. 2015). The systematic inflammatory diseases, such as rheumatoid arthritis, consequently display reduced testosterone levels. The pro-inflammatory cytokine TNF- $\alpha$ puts direct inhibition on LH function and subsequently, leading to low testosterone and male subfertility (Iwasa et al. 2009). Therefore, the increased systematic inflammatory cytokines in the serum of obesity males can induce a loss of androgen production at various levels of the hypothalamic-pituitary-Leydig cell axis.

In testis, pro-inflammatory cytokines can directly impair the seminiferous epithelium. Sertoli cells are in response to many of these pro-inflammatory cytokines, most notably IL-1, TNF- $\alpha$ and interferon. It has been postulated that these molecules affect the expression and assembly of the junctional proteins, e.g. zonulin/zonula occludens-1 (ZO-1), occludin, claudins and actinmyosin cytoskeletal proteins, thereby induce opening of the cell junctions between the adjacent Sertoli cells and lead to disturbances in the niche of seminiferous epithelium essential for spermatogenesis (Zhang et al. 2014, Chojnacka et al. 2016, Li et al. 2016, Stanton 2016). In fact, impaired BTB and decreased expression of junctional proteins in Sertoli cell have been observed in many obese animal models induced by diet (Liu et al. 2014, Fan et al. 2015).

Additionally, sperm maturation in epididymis is crucial for sperm to acquire the motile ability and fertile capacity. The epididymal epithelium transports proteins and lipids through epididymosomes to the sperm membrane, for which is necessary for sperm maturation (Sullivan 2015). Pro-inflammatory state induced by obesity can also damage epididymal epithelium function, by altering the environment within the epididymis, modifying the epididymosomes content and increasing the influx of neutrophils and macrophages to the epididymial lumen, resulting in higher cytokine expression and epithelial apoptosis, thus impeding sperm maturation and fertilization ability. Consequently, the presence of pro-inflammatory cytokines produced 
within the testis and epididymis or entered from the circulation during systematic inflammation, impinge upon the critical regulations of the spermatogenesis and sperm maturation.

\section{Obesity enhances oxidative stress}

One of the main factors relevant to disrupted sperm function in obese males is the oxidative stress caused by excess of reactive oxygen species (ROS), mainly including superoxide anion, nitric oxide, hydroxyl radical and oxidants. ROS can be produced normally in cellular metabolism, whereas in excessive state, it can induce oxidative stress and cause damage to DNA and plasma membrane integrity in sperm and increase stress on the testicular environment as well (Rato et al. 2014). Obesity, associated with the chronic inflammatory state, causes a higher metabolic rate and an increased ROS formation in testicular tissue, reproductive tract and semen. The pro-inflammatory cytokines, such as IL- 6 and TNF- $\alpha$, disrupt the seminiferous epithelium and epididymal epithelium by creating high levels of ROS. Additionally, inflammatory that attracts infiltrating phagocytic leukocytes are also capable of inducing oxidative stress in the male reproductive tract (Henkel 2011, Lavranos et al. 2012). Several studies have shown that oxidative stress in semen and testis were positive correlations to the increase in BMI and sperm DNA damage, and negative correlation to the decreased sperm motility and acrosome reaction (Bakos et al. 2011, Tunc et al. 2011). Thus, obviously, excessive oxidative stress is one of the potential mechanisms leading to poor sperm quality in obese males.

Besides, raised gonadal temperature in obese male may also contribute to altered sperm parameters. The process of spermatogenesis is highly sensitive to heat, with optimal temperature ranging between $34^{\circ} \mathrm{C}$ and $35^{\circ} \mathrm{C}$ in human. However, in obese male, increased scrotal adiposity directly leads to increases in gonadal heat (Garolla et al. 2015). Definitely, increased testicular heat can substantially reduce sperm motility and concentration and increase sperm DNA damage and sperm oxidative stress as well (Du Plessis et al. 2010).

Furthermore, a positive correlation exists between increasing $\mathrm{BMI}$ and higher sperm/seminal plasma ROS levels (Tunc et al. 2011, Taha et al. 2016). In particular, spermatozoa are individually susceptible to oxidative stress owing to their specially simplified organelles and limited antioxidant defensive capacity. In spermatozoa, ROS are mainly generated from the sperm mitochondria and in normal condition, they may be facilitated with sperm-egg recognition, fusion and fertilization later (Amaral et al. 2013); however, high levels of ROS prone to attack the lipids in sperm plasma membrane as well as the DNA in nucleus and mitochondria (Aitken et al. 2016).

\section{Obesity impairs sperm parameters}

The effect of male obesity on sperm parameters, such as sperm concentration, sperm motility and morphology, has been well documented in human and animal models. Many clinic investigations show that abnormal semen parameters can attribute to obesity including decreased sperm concentration, decreased sperm motility and increased abnormal morphology (Shukla et al. 2014, Guo et al. 2017). Actually, obese men are more likely to exhibit a reduction in semen quality than men with a normal weight and responsible to high risk of infertility. Consistently, abnormal sperm parameters including reduced sperm motility, decreased sperm counts and increased sperm deformity are also observed in the animal models with diet-induced obesity, thereby result in male subfertility (Bakos et al. 2011, Fernandez et al. 2011, Fan et al. 2015). On the other hand, it was verified that many factors altered in obese male may impair sperm quality including sexual hormone imbalance, oxidative stress and chronic inflammation. Notably, there is also some evidence indicating that weight loss, by exercise, lifestyle changes or bariatric surgery, can efficiently result in increased serum testosterone levels and sperm count (Hakonsen et al. 2011, Palmer et al. 2012), suggesting benefits for a possible weight loss on male fertility.

Moreover, a preliminary study reports that acrosome reaction, both spontaneous acrosome reaction and progesterone-induced acrosome reaction, is impaired in obese men (Samavat et al. 2014). Similarly, declined sperm acrosome reaction induced by calcium ionophore A23187 is also observed in diet-induced obese mouse model (Fan et al. 2015). Although the correlation between male obesity and sperm acrosome reaction is sparsely documented, it is reasonable that the impact of obesity on spermatogenesis and sperm maturation, which results in oxidative stress and membranous lipids alteration, may also cause some defects in acrosome reaction.

Additionally, several comparative proteomic studies have been conducted to illuminate the mechanisms of obesity's influence on sperm quality. Using difference gel electrophoresis or liquid chromatography tandem mass spectrometry (LC-MS), differential expressed proteins in spermatozoa from obese males are identified (Paasch et al. 2011, Liu et al. 2015). The low abundant proteins in obesity-associated asthenozoospermia are mainly associated with an array of biological functions including actin organization, flagellar assembly, vesicular traffic, protein degradation and stress resistance, and most of these proteins are involved in acrosome biogenesis, nuclear reshaping and flagellum formation during spermiogenesis that may directly causes abnormal sperm function. 


\section{Obesity increases sperm DNA damage}

In general, the backbone of the DNA helix is frequently cleaved in spermatozoa owing to the uncondensed DNA and results in either single-strand breaks (SSB) or doublestrand breaks (DSB). DNA fragmentation index (DFI) is a parameter representing the percent of spermatozoa in a semen sample that have single/DS breaks in nuclear DNA. In clinics, DFI at $3-5 \%$ is considered normal, whereas rise to $25-30 \%$ may increase the risk of infertility (Bungum et al. 2011).

The integrity of DNA in the sperm nucleus is an important determinant of semen quality since it is vital for fertilization rates, embryo quality, pregnancy rates and miscarriage rates as well. There are numerous human and animal studies to show the significant negative associations between obesity and sperm DNA integrity (Kort et al. 2006, Chavarro et al. 2010, MacDonald et al. 2010, Bakos et al. 2011, Fariello et al. 2012, Duale et al. 2014). Although various methods are applied to measure sperm DNA integrity, such as terminaldeoxynucleoitidyl transferase-mediated nick end labeling (TUNEL), single-cell gel electrophoresis (Comet) assay and sperm chromatin structure assay (SCSA), the most results consistently confirm the relationship between obesity and increased DNA damage. One of the main contributors in obesity for sperm DNA structure damage is ROS. The oxidative attack particular to sperm DNA can lead to DNA fragmentation directly, as well as to cause the formation of base adducts particularly 8-hydroxy-2'-deoxyguanosine $(8 \mathrm{OH}-\mathrm{dG})$, which results in base mismatch and DNA mutation (De luliis et al. 2009, Aitken et al. 2016). Meanwhile, the replacement of histone by protamines in late round spermatids also plays a critical role in sperm DNA protection. Histone acetylation is necessary for histones replacement by protamines, and alterations in histone acetylation are commonly found in the diet-induced obese mouse models, resulting in increased levels of DNA damage (Gaucher et al. 2010, Palmer et al. 2011, Davidson et al. 2015). On the other hand, because of the limitation in antioxidant defensive capacity and defectiveness in DNA repair system, the DNA damage induced by ROS in spermatozoa is particularly crippling and increases the risk of failure in further fertilization and embryonic development (Gavriliouk \& Aitken 2015).

\section{Obesity alters sperm lipid composition}

The sperm membrane is composed of various saturated fatty acids (i.e. myristic acid, palmitic acid, stearic acid etc.) and unsaturated fatty acids (i.e. palmitoleic acid, oleic acid, linoleic acid, arachidonic acid, docosahexaenoic acid etc.). The fatty acid composition of spermatozoa is important for the sperm function, including sperm motility, viability and fertility (Aksoy et al. 2006, Martinez-Soto et al. 2013,
Gangwar \& Atreja 2015, Andersen et al. 2016). The polyunsaturated fatty acids in spermatozoa, especially docosahexaenoic acid (DHA), are positively associated with sperm concentration, morphology and motility (Aksoy et al. 2006, Tavilani et al. 2007, Keber et al. 2013). The membranal lipids of the spermatozoa are mainly determined during spermatogenesis in testis and sperm maturation in epididymis. Therefore, the fatty acid composition of spermatozoa is also in relation to $\mathrm{BMI}$, which consists with the changes of inflammatory and oxidative stress in testis and epididymis. Indeed, BMI is negatively correlated with sperm DHA and palmitic acid levels (Andersen et al. 2016). The fact indicates that changes in the fatty acid composition of spermatozoa could be one of the mechanisms underlying reduced sperm quality in men with high BMI.

Meanwhile, membranal cholesterol is a main constituent in spermatozoa, which is quite various during sperm maturation and capacitation. The membranal cholesterol efflux that removes off cholesterol from sperm membrane during sperm capacitation is essential for modifying the membranal fluidity and further contributes to sperm motility maintenance and normal acrosome reaction (Wertheimer et al. 2008, Whitfield et al. 2015). Both clinic and animal studies have revealed the significant rise in sperm cholesterol content in obese males. These changes to sperm are proposed to cause sperm morphological abnormalities, decreased motility and premature acrosome reaction (Schisterman et al. 2014).

Normally, the membranal constituents of spermatozoa are composed of high contents of unsaturated fatty acids, with especially high levels of DHA that contributes up to $30 \%$ of the total fatty acid composition (Aksoy et al. 2006, Tavilani et al. 2007, Andersen et al. 2016). However, the membranous unsaturated fatty acids are susceptible to ROS and result in lipid peroxidation (Henkel 2011, Aitken et al. 2016). Hence, induced by excess amount of ROS in obese males may lead to lipid peroxidation that is related to poor membranal lipid fluidity and further affect sperm motility and acrosome reaction.

\section{Obesity influences sperm epigenetic modification}

Epigenetic modifications, such as DNA methylation and hydroxymethylation, histone modifications and noncoding RNA expression, modulate the transcription intensity and regulate gene expression in time and space without altering the genetic information in DNA. Both genetic and environmental factors can affect the epigenetic modifications and eventually influence the phenotype. Obesity is considered as a metabolic disorder resulting from the obesogenic environment such as high energy intake and low exercise rate. However, recent studies on epigenetic modifications influenced by obesity demonstrate that alterations in DNA methylation are a consequence of increased BMI (Dick et al. 2014, 
Ozanne 2015, Wang et al. 2016, Mendelson et al. 2017, Wahl et al. 2017).

Moreover, some clinical and animal studies suggest that paternal obesity may also have an impact on the metabolic health for his and/or her offspring and grandoffspring, which means that children born from obese parents are more likely to develop childhood obesity and suffer from adverse metabolic diseases (Fullston et al. 2015, McPherson et al. 2015, Slyvka et al. 2015, Chowdhury et al. 2016, Hur et al. 2017, Lecomte et al. 2017). Meanwhile, it is equally clear that children from obese fathers are at higher risk of developing metabolic disease in later life, for which is independent of their mother's body weight. Current evidences further indicate that obesity and its related metabolic comorbidities inherited across generations through nongenetic mechanisms are dependent on the epigenetic modification in gametes (Grandjean et al. 2015, Terashima et al. 2015, Soubry et al. 2016, Hur et al. 2017). Thus, it is believed that epigenetic modifications in sperm can be influenced by obesity and inherited trans-generation, although the research about obesityrelated epigenetic modifications in sperm are few concerned on.

As known, methylation of DNA and acetylation of histones are dynamic phenomena during spermatogenesis, by which is vital for the normal processes of spermatogenesis and fundamental for a successful pregnancy. DNA methylation is the reversible and heritable attachment of a methyl group to a nucleotide. The most common form of DNA methylation occurs at the $5^{\prime}$ carbon of cytosine in CpG dinucleotides, creating 5-methylcytosine. DNA methylation in sperm is associated with acetylation of histones, resulting in its replacement by protamines (Delaval et al. 2007). In particular, DNA methylation in spermatozoa displays two statuses, in which are either closed to no methylation or very high methylation, and methylated CpGs are almost exclusively found in protamine-associated DNA (Hammoud et al. 2009, Donkin et al. 2016). However, the extent of histone replacement and DNA methylation in sperm varies widely on a species-specific basis. A genomewide study reports that 9081 unique genes in sperm are differentially methylated between obese men and normal lean men, which are enrichment for the term 'nervous system development' (Donkin et al. 2016). Additionally, in high-fat diet-induced obesity rat model, numerous differentially methylated regions corresponding to 92 genes involved in cellular localization, transport and metabolic processes are identified in the spermatozoa and some differentially methylated regions are inherited trans-generation (de Castro Barbosa et al. 2015). The methylation of DNA in sperm is susceptible to environmental factors that might result in methylation status changes.

Furthermore, the presence of non-coding RNA in sperm from many species may have post-fertilization functions including transmission of acquired characteristics (Miller \& Ostermeier 2006, Sendler et al. 2013, Gapp et al. 2014). The non-coding RNA in sperm contains ribosomal RNA (rRNA), microRNAs (miRNA), PIWI-interacting RNAs (piRNA), small nucleolar RNA (snoRNA), small nuclear RNA (snRNA) and tRNAderived fragments (tRFs). Analysis of the non-coding RNA content in sperm from either human or rat model reveals that the expression levels of several miRNAs, piRNAs, tRFs and snRNA fragments were altered in the spermatozoa from obese males (de Castro Barbosa et al. 2015, Donkin et al. 2016). Some of the differential expressed piRNA are speculated to modulate the expression of genes involved in behavior and food intake and may participate in their offspring's predisposition to obesity (Donkin et al. 2016). On the other hand, the altered miRNA let-7c expression in sperm concurs that in adipose tissue from the offspring, suggesting the transgenerational inheritance of metabolic dysfunction sired by obese fathers (de Castro Barbosa et al. 2015, Chen et al. 2016b). Therefore, epigenetics may provide a key for elucidation of the intergenerational influences on obesity.

In addition to the adverse effects induced by obesity on male sperm epigenetic modification, there are several evidences suggesting that some other negative impacts may be transmitted to the offspring (de Castro Barbosa et al. 2015, Fullston et al. 2015, Chen et al. 2016a, Chowdhury et al. 2016, Hur et al. 2017, Lecomte et al. 2017). For instance, epidemiologic evidences showed that environmental challenges imposed on the father, such as stress, specific diets, toxins, tobacco smoking and alcohol consumption, have been found to influence the development of the offspring via the non-genetic alterations within sperm including small non-coding RNAs, DNA damage, DNA methylation and histone modifications (Chen et al. 2016b, Rando 2016, Schagdarsurengin \& Steger 2016, Fullston et al. 2017).

\section{Conclusion}

In summary, it gradually unveils a fact that male obesity has negative impacts on fertility, sperm function and on the health of the offspring for a long term. Male obesity alters the environment essential for spermatogenesis and sperm maturation, including HPG axis-related sexual hormone imbalance, increased scrotal temperature, induced chronic inflammation and oxidative stress in testis and epididymis and declined Sertoli cell activity. The impaired spermatogenesis and sperm maturation can further cause poor sperm quality, including declined sperm motility, inappropriate lipid composition, increased ROS and DNA damage and abnormal epigenetic modification that may be transgenerational transmitted, finally leading to male subfertility or infertility indeed (Fig. 1). 


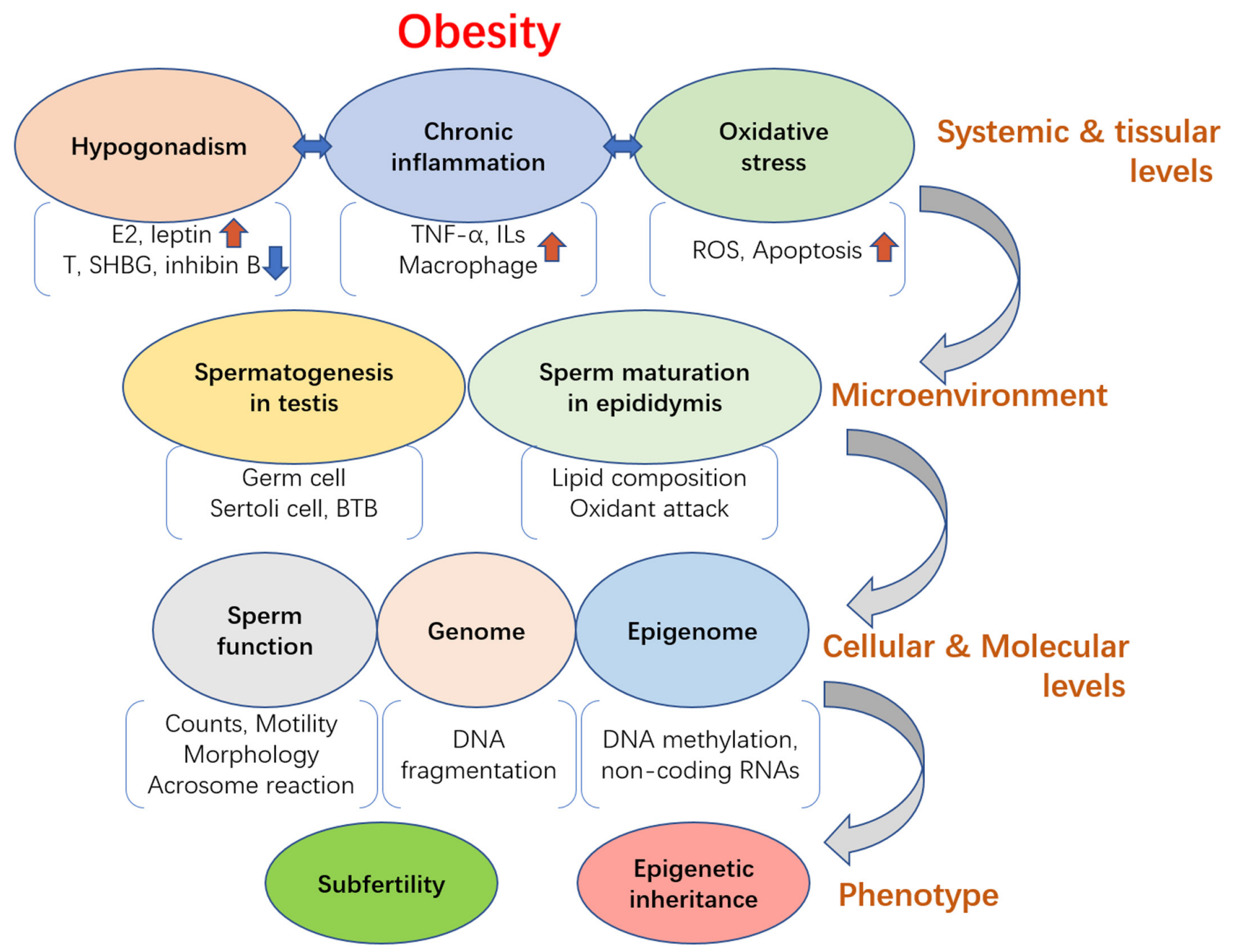

Figure 1 Effects of obesity on male fertility. Male obesity can lead to hypothalamic pituitary gonadal (HPG) axis-related hormone imbalance, induce chronic inflammation and enhance oxidative stress at both systemic and tissue levels. Therefore, the environment that is essential for spermatogenesis in testis and sperm maturation in epididymis such as Sertoli cell activity, BTB integrity and epididymal epithelium activity is gradually impaired by hormone deficiency, inflammation and oxidative attack. Then, the impaired spermatogenesis and sperm maturation can cause poor sperm quality, including declined sperm concentration and motility, inappropriate lipid composition, increased DNA damage and abnormal epigenetic modification, finally leading to male subfertility and health problems that may be transmitted to the offspring via epigenetic inheritance.

Nevertheless, the mechanisms of obesity that influence male reproduction remain somewhat unclear and still need to be further investigated, although the molecular alterations associated with obesity have been generally reported (Craig et al. 2017, Oliveira et al. 2017). For instance, among the multiple factors relevant to male subfertility associated with obesity, inflammation in reproductive system is one of what have been overlooked in previous studies. Obesity-related chronic inflammation is considered to raise the risk of cardiovascular disease, tumorigenesis, diabetes and etc., which means that the systematic chronic inflammation alters the individual homeostasis. Particularly in reproductive system that is essential for spermatogenesis and sperm maturation, chronic inflammation can affect the sperm fertilizing capability as well as the sperm epigenome. Thus, the inflammatory indicators in semen could potentially be a useful evaluation standard for sperm quality and are worthy of in-depth exploring. Meanwhile, the sperm epigenetic alterations induced by obesity will pass on to the subsequent generation and may result in the metabolic changes in the offspring even in the grandoffspring. Therefore, it is crucial to understand the changes of key epigenetic signatures in sperm induced by obesity and the transmission of these fingerprints across generations. Besides, based on the mechanism of epigenetic alteration and inheritance occurring in male obesity, it may be easier to explore the phenotypic inheritance in other types of environmental or health challenges, such as smoking, aging, nervousness and toxin. 


\section{Declaration of interest}

The authors declare that there is no conflict of interest that could be perceived as prejudicing the impartiality of this review.

\section{Funding}

This research project was supported by grants from National Natural Science Foundation of China (No. 81370752 and No. 81571487), the Science and Technology Commission of Shanghai Municipality (No. 16ZR1418600).

\section{Acknowledgments}

The authors thank Prof. Peter Reinach for his editorial assistance.

\section{References}

Aitken RJ, Gibb Z, Baker MA, Drevet J \& Gharagozloo P 2016 Causes and consequences of oxidative stress in spermatozoa. Reproduction Fertility and Development 28 1-10. (doi:10.1071/RD15325)

Aksoy Y, Aksoy H, Altinkaynak K, Aydin HR \& Ozkan A 2006 Sperm fatty acid composition in subfertile men. Prostaglandins, Leukotrienes and Essential Fatty Acids 75 75-79. (doi:10.1016/j.plefa.2006.06.002)

Amaral A, Lourenço B, Marques M \& Ramalho-Santos J 2013 Mitochondria functionality and sperm quality. Reproduction 146 163-174. (doi:10.1530/REP-13-0178)

Andersen JM, Rønning PO, Herning H, Bekken SD, Haugen TB \& Witczak O 2016 Fatty acid composition of spermatozoa is associated with BMI and with semen quality. Andrology 4 857-865. (doi:10.1111/ andr.12227)

Bakos HW, Mitchell M, Setchell BP \& Lane M 2011 The effect of paternal diet-induced obesity on sperm function and fertilization in a mouse model. International Journal of Andrology 34 402-410. (doi:10.1111/ j.1365-2605.2010.01092.x)

Bungum M, Bungum L \& Giwercman A. 2011 Sperm chromatin structure assay (SCSA): a tool in diagnosis and treatment of infertility. Asian Journal of Andrology 13 69-75. (doi:10.1038/aja.2010.73)

Chavarro JE, Toth TL, Wright DL, Meeker JD \& Hauser R 2010 Body mass index in relation to semen quality, sperm DNA integrity, and serum reproductive hormone levels among men attending an infertility clinic. Fertility and Sterility 93 2222-2231. (doi:10.1016/j. fertnstert.2009.01.100)

Chen Q, Yan M, Cao Z, Li X, Zhang Y, Shi J, Feng GH, Peng H, Zhang $\mathbf{X}$, Zhang Y et al. 2016a Sperm tsRNAs contribute to intergenerational inheritance of an acquired metabolic disorder. Science 351 397-400. (doi:10.1126/science.aad7977)

Chen Q, Yan W \& Duan E $2016 b$ Epigenetic inheritance of acquired traits through sperm RNAs and sperm RNA modifications. Nature Reviews Genetics 17 733-743. (doi:10.1038/nrg.2016.106)

Cheng CY, Wong EW, Yan HH \& Mruk DD 2010 Regulation of spermatogenesis in the microenvironment of the seminiferous epithelium: new insights and advances. Molecular and Cellular Endocrinology 315 49-56. (doi:10.1016/j.mce.2009.08.004)

Chojnacka K, Bilinska B \& Mruk DD 2016 Interleukin 1alpha-induced disruption of the Sertoli cell cytoskeleton affects gap junctional communication. Cellular Signalling 28 469-480. (doi:10.1016/j. cellsig.2016.02.003)

Chowdhury SS, Lecomte V, Erlich JH, Maloney CA \& Morris MJ 2016 Paternal high fat diet in rats leads to renal accumulation of lipid and tubular changes in adult offspring. Nutrients 8 E521. (doi:10.3390/ nu8090521)

Craig JR, Jenkins TG, Carrell DT \& Hotaling JM 2017 Obesity, male infertility, and the sperm epigenome. Fertility and Sterility 107 848-859. (doi:10.1016/j.fertnstert.2017.02.115)

Cui X, Jing X, Wu X \& Yan M 2016 Protective effect of resveratrol on spermatozoa function in male infertility induced by excess weight and obesity. Molecular Medicine Reports 14 4659-4665. (doi:10.3892/ mmr.2016.5840)

Cui H, López M \& Rahmouni K 2017 The cellular and molecular bases of leptin and ghrelin resistance in obesity. Nature Reviews Endocrinology 13 338-351. (doi:10.1038/nrendo.2016.222)

Davidson LM, Millar K, Jones C, Fatum M \& Coward K 2015 Deleterious effects of obesity upon the hormonal and molecular mechanisms controlling spermatogenesis and male fertility. Human Fertility $\mathbf{1 8}$ 184-193. (doi:10.3109/14647273.2015.1070438)

de Castro Barbosa T, Ingerslev LR, Alm PS, Versteyhe S, Massart J, Rasmussen M, Donkin I, Sjögren R, Mudry JM, Vetterli L et al. 2016 High-fat diet reprograms the epigenome of rat spermatozoa and transgenerationally affects metabolism of the offspring. Molecular Metabolism 5 184-97. (doi:10.1016/j.molmet.2015.12.002)

De Iuliis GN, Thomson LK, Mitchell LA, Finnie JM, Koppers AJ, Hedges A, Nixon B \& Aitken RJ 2009 DNA damage in human spermatozoa is highly correlated with the efficiency of chromatin remodeling and the formation of 8-hydroxy-2'-deoxyguanosine, a marker of oxidative stress. Biology of Reproduction 81 517-524. (doi:10.1095/biolreprod.109.076836)

Delaval K, Govin J, Cerqueira F, Rousseaux S, Khochbin S \& Feil R 2007 Differential histone modifications mark mouse imprinting control regions during spermatogenesis. EMBO Journal 26 720-729. (doi:10.1038/ sj.emboj.7601513)

Divella R, De Luca R, Abbate I, Naglieri E \& Daniele A 2016 Obesity and cancer: the role of adipose tissue and adipo-cytokines-induced chronic inflammation. Journal of Cancer 7 2346-2359. (doi:10.7150/ jca.16884)

Dick KJ, Nelson CP, Tsaprouni L, Sandling JK, Aïssi D, Wahl S, Meduri E, Morange PE, Gagnon F, Grallert H et al. 2014 DNA methylation and body-mass index: a genome-wide analysis. Lancet 383 1990-1998. (doi:10.1016/S0140-6736(13)62674-4)

Donkin I, Versteyhe S, Ingerslev LR, Qian K, Mechta M, Nordkap L, Mortensen B, Appel EV, Jørgensen N, Kristiansen VB et al. 2016 Obesity and bariatric surgery drive epigenetic variation of spermatozoa in humans. Cell Metabolism 23 369-378. (doi:10.1016/j.cmet.2015.11.004)

Du Plessis SS, Cabler S, McAlister DA, Sabanegh E \& Agarwal A 2010 The effect of obesity on sperm disorders and male infertility. Nature Reviews Urology 7 153-161. (doi:10.1038/nrurol.2010.6)

Duale N, Steffensen IL, Andersen J, Brevik A, Brunborg G \& Lindeman B 2014 Impaired sperm chromatin integrity in obese mice. Andrology $\mathbf{2}$ 234-243. (doi:10.1111/j.2047-2927.2013.00178.x)

Dulloo AG \& Montani JP 2012 Body composition, inflammation and thermogenesis in pathways to obesity and the metabolic syndrome: an overview. Obesity Reviews 13 1-5. (doi:10.1111/j.1467789X.2012.01032.x)

Dupont C, Faure C, Sermondade N, Boubaya $M$, Eustache F, Clément $P$, Briot P, Berthaut I, Levy V, Cedrin-Durnerin I et al. 2013 Obesity leads to higher risk of sperm DNA damage in infertile patients. Asian Journal of Andrology 15 622-625. (doi:10.1038/aja.2013.65)

Fan Y, Liu Y, Xue K, Gu G, Fan W, Xu Y \& Ding Z 2015 Diet-induced obesity in male $\mathrm{C} 57 \mathrm{BL} / 6$ mice decreases fertility as a consequence of disrupted blood-testis barrier. PLOS ONE 14 e0120775. (doi:10.1371/journal. pone.0120775)

Fariello RM, Pariz JR, Spaine DM, Cedenho AP, Bertolla RP \& Fraietta R 2012 Association between obesity and alteration of sperm DNA integrity and mitochondrial activity. BJU International 110 863-867. (doi:10.1111/j.1464-410X.2011.10813.x)

Fernandez CD, Bellentani FF, Fernandes GS, Perobelli JE, Favareto AP, Nascimento AF, Cicogna AC \& Kempinas WD 2011 Diet-induced obesity in rats leads to a decrease in sperm motility. Reproductive Biology and Endocrinology 9 32. (doi:10.1186/1477-7827-9-32)

Fullston T, McPherson NO, Owens JA, Kang WX, Sandeman LY \& Lane M 2015 Paternal obesity induces metabolic and sperm disturbances in male offspring that are exacerbated by their exposure to an 'obesogenic' diet. Physiological Reports 3 e12336. (doi:10.14814/phy2.12336)

Fullston T, McPherson NO, Zander-Fox D \& Lane M 2017 The most common vices of men can damage fertility and the health of the next generation. Journal of Endocrinology 234 F1-F6. (doi:10.1530/JOE-160382)

Gangwar DK \& Atreja SK 2015 Signalling events and associated pathways related to the mammalian sperm capacitation. Reproduction in Domestic Animals 50 705-711. (doi:10.1111/rda.12541) 
Gapp K, Jawaid A, Sarkies P, Bohacek J, Pelczar P, Prados J, Farinelli L, Miska E \& Mansuy IM 2014 Implication of sperm RNAs in transgenerational inheritance of the effects of early trauma in mice. Nature Neuroscience 17 667-669. (doi:10.1038/nn.3695)

Garolla A, Torino M, Miola P, Caretta N, Pizzol D, Menegazzo M, Bertoldo A \& Foresta C 2015 Twenty-four-hour monitoring of scrotal temperature in obese men and men with a varicocele as a mirror of spermatogenic function. Human Reproduction 30 1006-1013. (doi:10.1093/humrep/ dev057)

Gaucher J, Reynoird N, Montellier E, Boussouar F, Rousseaux S \& Khochbin S 2010 From meiosis to postmeiotic events: the secrets of histone disappearance. FEBS Journal 277 599-604. (doi:10.1111/j.17424658.2009.07504.x)

Gavriliouk D \& Aitken RJ 2015 Damage to sperm DNA mediated by reactive oxygen species: its impact on human reproduction and the health trajectory of offspring. Advances in Experimental Medicine and Biology 868 23-47. (doi:10.1007/978-3-319-18881-2_2)

Grandjean V, Fourré S, De Abreu DA, Derieppe MA, Remy JJ \& Rassoulzadegan M 2015 RNA-mediated paternal heredity of dietinduced obesity and metabolic disorders. Scientific Reports 518193. (doi:10.1038/srep18193)

Griffin C, Lanzetta N, Eter L \& Singer K 2016 Sexually dimorphic myeloid inflammatory and metabolic responses to diet-induced obesity. American Journal of Physiology - Regulatory, Integrative and Comparative Physiology 311 R211-R216. (doi:10.1152/ajpregu.00136.2016)

Guo D, Wu W, Tang Q, Qiao S, Chen Y, Chen M, Teng M, Lu C, Ding H, Xia Y et al. 2017 The impact of BMl on sperm parameters and the metabolite changes of seminal plasma concomitantly. Oncotarget $\mathbf{8}$ 48619-48634. (doi:10.18632/oncotarget.14950)

Håkonsen LB, Thulstrup AM, Aggerholm AS, Olsen J, Bonde JP, Andersen CY, Bungum M, Ernst EH, Hansen ML, Ernst EH et al. 2011 Does weight loss improve semen quality and reproductive hormones? Results from a cohort of severely obese men. Reproductive Health 824 . (doi:10.1186/1742-4755-8-24)

Hammoud SS, Nix DA, Zhang H, Purwar J, Carrell DT \& Cairns BR 2009 Distinctive chromatin in human sperm packages genes for embryo development. Nature 460 473-478. (doi:10.1038/nature08162)

Henkel RR 2011 Leukocytes and oxidative stress: dilemma for sperm function and male fertility. Asian Journal of Andrology 13 43-52. (doi:10.1038/aja.2010.76)

Huang G, Yuan M, Zhang J, Li J, Gong D, Li Y, Zhang J, Lin P \& Huang L 2016 IL-6 mediates differentiation disorder during spermatogenesis in obesity-associated inflammation by affecting the expression of Zfp637 through the SOCS3/STAT3 pathway. Scientific Reports 628012. (doi:10.1038/srep28012)

Hur SS, Cropley JE \& Suter CM 2017 Paternal epigenetic programming: evolving metabolic disease risk. Journal of Molecular Endocrinology $\mathbf{5}$ 159-168. (doi:10.1530/JME-16-0236)

Iwasa T, Matsuzaki T, Murakami M, Kinouchi R, Ogata R, Kuwahara A, Yasui T \& Irahara M 2009 Neonatal lipopolysaccharide exposure attenuates the homotypic stress-induced suppression of LH secretion in adulthood in male rat. International Journal of Developmental Neuroscience $\mathbf{2 7}$ 345-349. (doi:10.1016/j.ijdevneu.2009.03.004)

Jensen TK, Andersson AM, Jørgensen N, Andersen AG, Carlsen E, Petersen JH \& Skakkebaek NE 2004 Body mass index in relation to semen quality and reproductive hormones among 1,558 Danish men. Fertility and Sterility 82 863-870. (doi:10.1016/j.fertnstert.2004.03.056)

Keber R, Rozman D \& Horvat S 2013 Sterols in spermatogenesis and sperm maturation. Journal of Lipid Research 54 20-33. (doi:10.1194/ jlr.R032326)

Kolb R, Sutterwala FS \& Zhang W 2016 Obesity and cancer: inflammation bridges the two. Current Opinion in Pharmacology 29 77-89. (doi:10.1016/j.coph.2016.07.005)

Kort HI, Massey JB, Elsner CW, Mitchell-Leef D, Shapiro DB, Witt MA \& Roudebush WE 2006 Impact of body mass index values on sperm quantity and quality. Journal of Andrology 27 450-452. (doi:10.2164/ jandrol.05124)

Lavranos G, Balla M, Tzortzopoulou A, Syriou V \& Angelopoulou R 2012 Investigating ROS sources in male infertility: a common end for numerous pathways. Reproductive Toxicology 34 298-307. (doi:10.1016/j. reprotox.2012.06.007)
Lecomte V, Maloney CA, Wang KW \& Morris MJ 2017 Effects of paternal obesity on growth and adiposity of male rat offspring. American Journal of Physiology-Endocrinology and Metabolism 312 117-125. (doi:10.1152/ ajpendo.00262.2016)

Li N, Tang El \& Cheng CY 2016 Regulation of blood-testis barrier by actin binding proteins and protein kinases. Reproduction $15129-41$. (doi:10.1530/REP-15-0463)

Lie PP, Cheng CY \& Mruk DD 2013 Signalling pathways regulating the blood-testis barrier. International Journal of Biochemistry and Cell Biology 45 621-625. (doi:10.1016/j.biocel.2012.12.009)

Liu Y, Zhao W, Gu G, Lu L, Feng J, Guo Q \& Ding Z 2014 Palmitoylprotein thioesterase 1 (PPT1): an obesity-induced rat testicular marker of reduced fertility. Molecular Reproduction and Development 81 55-65. (doi:10.1002/mrd.22281)

Liu Y, Guo Y, Song N, Fan Y, Li K, Teng X, Guo Q \& Ding Z 2015 Proteomic pattern changes associated with obesity-induced asthenozoospermia. Andrology 3 247-259. (doi:10.1111/andr.289)

MacDonald AA, Herbison GP, Showell M \& Farquhar CM 2010 The impact of body mass index on semen parameters and reproductive hormones in human males: a systematic review with meta-analysis. Human Reproduction Update 16 293-311. (doi:10.1093/humupd/dmp047)

Mah PM \& Wittert GA 2010 Obesity and testicular function. Molecular and Cellular Endocrinology 316 180-186. (doi:10.1016/j.mce.2009.06.007)

Martínez-Soto JC, Landeras J \& Gadea J 2013 Spermatozoa and seminal plasma fatty acids as predictors of cryopreservation success. Andrology 1 365-375. (doi:10.1111/j.2047-2927.2012.00040.x)

Martins AD, Moreira AC, Sá R, Monteiro MP, Sousa M, Carvalho RA, Silva BM, Oliveira PF \& Alves MG 2015 Leptin modulates human Sertoli cells acetate production and glycolytic profile: a novel mechanism of obesity-induced male infertility? Biochimica et Biophysica Acta 1852 1824-1832. (doi:10.1016/j.bbadis.2015.06.005)

Martins AD, Sá R, Monteiro MP, Barros A, Sousa M, Carvalho RA, Silva BM, Oliveira PF \& Alves MG 2016 Ghrelin acts as energy status sensor of male reproduction by modulating Sertoli cells glycolytic metabolism and mitochondrial bioenergetics. Molecular and Cellular Endocrinology 434 199-209. (doi:10.1016/j.mce.2016.07.008)

McPherson NO \& Lane M 2015 Male obesity and subfertility, is it really about increased adiposity? Asian Journal of Andrology 17 450-458. (doi:10.4103/1008-682X.148076)

McPherson NO, Fullston T, Aitken RJ \& Lane M 2014 Paternal obesity, interventions, and mechanistic pathways to impaired health in offspring. Annals of Nutrition and Metabolism 64 231-238. (doi:10.1159/000365026)

Mendelson MM, Marioni RE, Joehanes R, Liu C, Hedman ÅK, Aslibekyan S, Demerath EW, Guan W, Zhi D, Yao C et al. 2017 Association of body mass index with DNA methylation and gene expression in blood cells and relations to cardiometabolic disease: a Mendelian randomization approach. PLoS Medicine $\mathbf{1 4}$ e1002215. (doi:10.1371/journal. pmed.1002215)

Michalakis K1, Mintziori G, Kaprara A, Tarlatzis BC \& Goulis DG 2013 The complex interaction between obesity, metabolic syndrome and reproductive axis: a narrative review. Metabolism 62 457-478. (doi:10.1016/j.metabol.2012.08.012)

Miller D \& Ostermeier GC 2006 Towards a better understanding of RNA carriage by ejaculate spermatozoa. Human Reproduction Update 12 757-767. (doi:10.1093/humupd/dml037)

Oliveira PF, Sousa M, Silva BM, Monteiro MP \& Alves MG 2017 Obesity, energy balance and spermatogenesis. Reproduction 153 R173-R185. (doi:10.1530/REP-17-0018)

Ozanne SE 2015 Epigenetic signatures of obesity. New England Journal of Medicine 372 973-974. (doi:10.1056/NEJMcibr1414707)

Paasch U, Heidenreich F, Pursche T, Kuhlisch E, Kettner K, Grunewald S, Kratzsch J, Dittmar G, Glander HJ, Hoflack B et al. 2011 Identification of increased amounts of eppin protein complex components in sperm cells of diabetic and obese individuals by difference gel electrophoresis. Molecular and Cellular Proteomics 10 M110.007187. (doi:10.1074/ mcp.M110.007187)

Palmer NO, Fullston T, Mitchell M, Setchell BP \& Lane M 2011 SIRT6 in mouse spermatogenesis is modulated by diet-induced obesity. Reproduction, Fertility and Development 23 929-939. (doi:10.1071/ RD10326) 
Palmer NO, Bakos HW, Owens JA, Setchell BP \& Lane M 2012 Diet and exercise in an obese mouse fed a high-fat diet improve metabolic health and reverse perturbed sperm function. American Journal of Physiology-Endocrinology and Metabolism 302 768-780. (doi:10.1152/ ajpendo.00401.2011)

Ramaswamy S \& Weinbauer GF 2015 Endocrine control of spermatogenesis: role of FSH and $\mathrm{LH} /$ testosterone. Spermatogenesis 4 e996025. (doi:10.1080/21565562.2014.996025)

Rando OJ 2016 Intergenerational transfer of epigenetic information in sperm. Cold Spring Harbor Perspectives in Medicine 6 a022988. (doi:10.1101/cshperspect.a022988)

Rato L, Alves MG, Cavaco JE \& Oliveira PF 2014 High-energy diets: a threat for male fertility? Obesity Reviews 15 996-1007. (doi:10.1111/ obr.12226)

Rey RA, Grinspon RP, Gottlieb S, Pasqualini T, Knoblovits P, Aszpis S, Pacenza N, Stewart Usher J, Bergadá I \& Campo SM 2013 Male hypogonadism: an extended classification based on a developmental, endocrine physiology-based approach. Andrology 1 3-16. (doi:10.1111/ j.2047-2927.2012.00008.x)

Samavat J, Natali I, Degl'Innocenti S, Filimberti E, Cantini G, Di Franco A, Danza G, Seghieri G, Lucchese M, Baldi E et al. 2014 Acrosome reaction is impaired in spermatozoa of obese men: a preliminary study. Fertility and Sterility 102 1274-1281. (doi:10.1016/j.fertnstert.2014.07.1248)

Schagdarsurengin U \& Steger K 2016 Epigenetics in male reproduction: effect of paternal diet on sperm quality and offspring health. Nature Reviews Urology 13 584-595. (doi:10.1038/nrurol.2016.157)

Schisterman EF, Mumford SL, Chen Z, Browne RW, Boyd Barr D, Kim S \& Buck Louis GM 2014 Lipid concentrations and semen quality: the LIFE study. Andrology 2 408-415. (doi:10.1111/j.2047-2927.2014.00198.x)

Sendler E, Johnson GD, Mao S, Goodrich RJ, Diamond MP, Hauser R \& Krawetz SA 2013 Stability, delivery and functions of human sperm RNAs at fertilization. Nucleic Acids Research 41 4104-4117. (doi:10.1093/ nar/gkt132)

Sermondade N, Faure C, Fezeu L, Shayeb AG, Bonde JP, Jensen TK, Van Wely M, Cao J, Martini AC, Eskandar M et al. 2013 BMI in relation to sperm count: an updated systematic review and collaborative metaanalysis. Human Reproduction Update 19 221-231. (doi:10.1093/ humupd/dms050)

Shukla KK, Chambial S, Dwivedi S, Misra S \& Sharma P 2014 Recent scenario of obesity and male fertility. Andrology 2 809-818. (doi:10.1111/andr.270)

Slyvka Y, Zhang Y \& Nowak FV 2015 Epigenetic effects of paternal diet on offspring: emphasis on obesity. Endocrine 48 36-46. (doi:10.1007/ s12020-014-0328-5)

Soubry A, Guo L, Huang Z, Hoyo C, Romanus S, Price T \& Murphy SK 2016 Obesity-related DNA methylation at imprinted genes in human sperm: results from the TIEGER study. Clinical Epigenetics 8 51. (doi:10.1186/ s13148-016-0217-2)

Stanton PG 2016 Regulation of the blood-testis barrier. Seminars in Cell and Developmental Biology 59 166-173. (doi:10.1016/j. semcdb.2016.06.018)

Sullivan R 2015 Epididymosomes: a heterogeneous population of microvesicles with multiple functions in sperm maturation and storage. Asian Journal of Andrology 17 726-729. (doi:10.4103/1008$682 X .155255)$

Taha EA, Sayed SK, Gaber HD, Abdel Hafez HK, Ghandour N, Zahran A \& Mostafa T 2016 Does being overweight affect seminal variables in fertile men? Reproductive BioMedicine Online 33 703-708. (doi:10.1016/j. rbmo.2016.08.023)
Tavilani H, Doosti M, Nourmohammadi I, Mahjub H, Vaisiraygani A, Salimi S \& Hosseinipanah SM 2007 Lipid composition of spermatozoa in normozoospermic and asthenozoospermic males. Prostaglandins, Leukotrienes and Essential Fatty Acids 77 45-50. (doi:10.1016/j. plefa.2007.07.001)

Terashima M, Barbour S, Ren J, Yu W, Han Y \& Muegge K 2015 Effect of high fat diet on paternal sperm histone distribution and male offspring liver gene expression. Epigenetics 10 861-871. (doi:10.1080/15592294. 2015.1075691)

Tsatsanis C, Dermitzaki E, Avgoustinaki P, Malliaraki N, Mytaras V \& Margioris AN 2015 The impact of adipose tissue-derived factors on the hypothalamic-pituitary-gonadal (HPG) axis. Hormones 14 549-562. (doi:10.14310/horm.2002.1649)

Tunc O, Bakos HW \& Tremellen K 2011 Impact of body mass index on seminal oxidative stress. Andrologia 43 121-128. (doi:10.1111/j.14390272.2009.01032.x)

World Health Organization 2014 Obesity and overweight. Fact sheet no. 311. (Available at: http://www.who.int/mediacentre/factsheets/ fs311/en/).

Wahl S, Drong A, Lehne B, Loh M, Scott WR, Kunze S, Tsai PC, Ried JS, Zhang W, Yang Y et al. 2017 Epigenome-wide association study of body mass index, and the adverse outcomes of adiposity. Nature 541 81-86. (doi:10.1038/nature20784)

Wang B, Gao W, Li J, Yu C, Cao W, Lv J, Pang Z, Cong L, Wang H, Wu X et al. 2016 Methylation loci associated with body mass index, waist circumference, and waist-to-hip ratio in Chinese adults: an epigenomewide analysis. Lancet 388 S21. (doi:10.1016/S0140-6736(16)31948-1)

Wertheimer EV, Salicioni AM, Liu W, Trevino CL, Chavez J, HernándezGonzález EO, Darszon A \& Visconti PE 2008 Chloride is essential for capacitation and for the capacitation-associated increase in tyrosine phosphorylation. Journal of Biological Chemistry 283 35539-35550. (doi:10.1074/jbc.M804586200)

Whitfield M, Pollet-Villard X, Levy R, Drevet JR \& Saez F 2015 Posttesticular sperm maturation, infertility, and hypercholesterolemia. Asian Journal of Andrology 17 742-748. (doi:10.4103/1008-682X.155536)

Youngson NA, Lecomte V, Maloney CA, Leung P, Liu J, Hesson LB, Luciani F, Krause L \& Morris MJ 2016 Obesity-induced sperm DNA methylation changes at satellite repeats are reprogrammed in rat offspring. Asian Journal of Andrology 18 930-936. (doi:10.4103/1008-682X.163190)

Zhang H, Yin Y, Wang G, Liu Z, Liu L \& Sun F 2014 Interleukin-6 disrupts blood-testis barrier through inhibiting protein degradation or activating phosphorylated ERK in Sertoli cells. Scientific Reports 44260. (doi:10.1038/srep04260)

Zhang E, Xu F, Liang H, Yan J, Xu H, Li Z, Wen X \& Weng J 2015 GLP-1 receptor agonist exenatide attenuates the detrimental effects of obesity on inflammatory profile in testis and sperm quality in mice. American Journal of Reproductive Immunology 74 457-466. (doi:10.1111/ aji.12420)

Received 15 March 2017

First decision 13 April 2017

Revised manuscript received 2 July 2017

Accepted 26 July 2017 